\title{
PRODUÇÃO DE LARVAS DE CURIMBATÁ (Prochilodus scrofa) SUBMETIDAS A DIFERENTES DENSIDADES DE ESTOCAGEM E NÍVEIS DE PROTEÍNA BRUTA NAS DIETAS.
}

\author{
PRODUCTION IN CURIMBATÁ (Prochilodus scrofa) LARVAE, EXPOSED TO DIFFERENT \\ STOCKING DENSITY AND DIFFERENT CRUDE PROTEIN LEVELS ON THE DIETS.
}

\author{
Teresa Cristina Ribeiro Dias Koberstein ${ }^{1}$ João Guilherme Durigan ${ }^{2}$
}

\section{RESUMO}

\begin{abstract}
O gênero Prochilodus é amplamente distribuído pela América do Sul, incluindo várias espécies que apresenta certo grau de endemismo nas diferentes bacias. Essas espécies alimentam-se basicamente de detritos orgânicos, organismos do benton, e alimentações artificiais. $O$ objetivo deste estudo foi testar três densidades de estocagem $(0,5,0,75$, e 1 larva/litro) $e$ dietas contendo dois níveis diferentes de proteína bruta $(35 e$ $40 \%$ PB) nos parâmetros do crescimento e na taxa da sobrevivência do curimbatá, Prochilodus scrofa. As larvas foram estocadas em aquários experimentais de 100 litros, mantidos com volume de 60 litros, com o fluxo de água contínuo, proveniente de poço semi-artesiano. A maior média foi proporcionada pela ração com $40 \%$ de $P B(1,66 g \pm 0,21)$. As diferenças foram significativas para os efeitos dos teores de PB sobre o ganho de peso e densidades de estocagem, na sobrevivência das larvas. Para o ganho de peso, as melhores médias foram obtidas com nivel de $40 \%$ de $P B(2,50 \mathrm{~g} \pm 0,40)$ e para a sobrevivência, as melhores taxas foram 94,45\% $\pm 19,32$ e 78,87\% $\pm 19,32$ nas densidades de 0,5 e 0,75 larvas/litro, respectivamente.
\end{abstract}

Palavras-chave: curimbatá, densidade de estocagem, Prochilodus scrofa, proteína bruta.

\section{SUMMARY}

Fish of the genus Prochilodus is widely spread in South America, showing endemic characteristics in some basins. It feeds basically on organic detritus, benton organisms, and artificial feeds. The purpose of this study was to test three stocking densities $(0.5,0.75$, and 1 fry/L) and diets with two different crude protein levels (35 and $40 \%$ CP) on the growth parameters and survival rate of curimbatá, Prochilodus scrofa.
Larvae were stocked in $100 \mathrm{~L}$ aquaria containing 60L, supplied with continuous water flow coming from an artesian well. There was a significant effect $(P<0.05)$ of the $40 \%$ CP diet on growth (body weight $=1.66 \mathrm{~g} \pm 0.21)$ of fish stocked at $0.5 \mathrm{fry} / \mathrm{L}$, at the $30^{\text {th }}$ experimental day. At the $68^{\text {th }}$ day, fish fed the $40 \%$ CP diet achieved the highest $(P<0.05)$ final body weight $(2.50 \mathrm{~g} \pm 0.40)$, and fish stocked at the densities 0.5 and 0.75 fry/L showed the highest survival rate, $94.45 \% \pm 19.32$ and $78.87 \% \pm 19.32$, respectively. Our results suggest that larvae curimbata may be fed exclusively with artificial diet after nine days-old.

Key words: curimbatá, stocking density, crude protein, Prochilodus scrofa.

\section{INTRODUÇÃO}

A alimentação das larvas de peixes, logo após, ou mesmo antes de absorver o saco vitelínico, quando atravessa o período crítico, corresponde um ponto de suma importância devido à elevada mortalidade que a falta de alimento pode provocar.Os primeiros alimentos de todas as formas jovens de peixes, independente da espécie ou hábito alimentar, logo após a reabsorção do saco vitelino, são os organismos do plâncton. As larvas podem ingerir diretamente os organismos do plâncton, entretanto, para algumas espécies, o fitoplâncton constitui apenas um elo inicial da cadeia alimentar, pois servem de alimento a protozoários e estes a rotíferos, microcustáceos, larvas de insetos, vermes e outros animais que,

\footnotetext{
${ }^{1}$ Zootecnista, doutora em aquicultura, Centro de Aqüicultura, Universidade Estadual Paulista, Via de Acesso Prof. Paulo Donato Castellane, s/n, Bairro Rural, 14870-000, Jaboticabal, SP. E-mail: crisdias@ caunesp.unesp.br. Autor para correspondência.

${ }^{\dagger}$ In memorian - Biólogo.
} 
por sua vez, constituem o alimento dos peixes (BASILE-MARTINS, 1984).

O desenvolvimento de dietas experimentais para a aqüicultura, dentro de sistema semiintensivo de produção, tem se baseado amplamente na nutrição e nas técnicas de fabricação pioneiras desenvolvidas pela indústria intensiva de frangos. $\mathrm{O}$ beneficiamento máximo das dietas artificiais só pode ser encontrado se o alimento for ingerido por completo e convertido em tecidos corporais sob a forma de crescimento dos peixes ou camarões (TACON, 1988). DIAS (1989) observou que, ao contrário das dietas naturais, as dietas artificiais não sofrem variações periódicas na composição bromatológica e, além disso, podem sofrer um rigoroso controle de qualidade durante o processo de fabricação.

O gênero Prochilodus é amplamente distribuído pela América do Sul, incluindo várias espécies que apresentam certo grau de endemismo nas diferentes bacias. Alimentam-se, basicamente de detritos orgânicos, fauna bentônica e, mesmo ração (CASTAGNOLLI, 1992).O objetivo do trabalho foi observar o desempenho de produção de larvas de curimbatá (Prochilodus scrofa), em três densidades de estocagem $(0,5,0,75$ e 1 larva/litro), e dois teores de proteína bruta (35 e 40\%) na ração.

\section{MATERIAL E MÉTODOS}

O experimento foi conduzido no Laboratório de Nutrição de Peixes do Centro de Aqüicultura da UNESP, campus de Jaboticabal durante 68 dias. Foram utilizadas larvas de curimbatá (Prochilodus scrofa) provenientes de uma desova induzida, com nove dias de vida e cultivadas em 18 caixas de cimento amianto, com 100 litros de capacidade e abastecimento de água de poço semiartesiano, individual contínuo e fluxo de 1 litro/minuto, mantidas com volume de 60 litros em cada caixa.

Foram testados seis tratamentos, em um delineamento inteiramente casualizado, em esquema fatorial $2 \times 3$, sendo dois teores de proteína bruta $(35 \%$ e $40 \%)$ e três densidades de cultivo $(0,5 ; 0,75$ e 1 larva/litro) com três repetições. Os animais foram amostrados aos 45 e 68 dias do experimento.

A tabela 1 apresenta a composição bromatológica das duas dietas experimentais. As rações foram moídas e peneiradas em malha $0,25 \mathrm{~mm}$ durante a primeira semana do experimento e, a cada semana que passava, as rações eram passadas por peneiras de malha 0,$35 ; 0,50 ; 0,71$ e $1,00 \mathrm{~mm}$, respectivamente.

Semanalmente, foram feitas coletas de água para análise em laboratório. Os parâmetros analisados e respectivos instrumentos de análise
Tabela 1 - Composição das dietas experimentais.

\begin{tabular}{lrr}
\hline \multirow{2}{*}{ Ingredientes } & \multicolumn{2}{c}{ Proteína bruta na dieta } \\
\cline { 2 - 3 } & $35 \%$ & $40 \%$ \\
\hline Farinha de peixe & 14,83 & 19,26 \\
Farinha de camarão & 10,00 & 10,00 \\
Ovo liofilizado & 12,40 & 12,40 \\
Farelo de soja & 20,00 & 25,00 \\
Levedura & 13,70 & 17,40 \\
Farelo de trigo & 5,00 & 5,00 \\
Farelo de arroz & 5,00 & 5,00 \\
Farelo de milho & 15,07 & 1,94 \\
Urucum & 3,00 & 3,00 \\
Suplemento mineral e vitamínico* & 1,00 & 1,00 \\
Proteína bruta (\%) & 35,06 & 40,04
\end{tabular}

*Composição por quilo de suplemento: vitamina A, 12.000UI; vitamina D3, 2.000 UI; vitamina E, 20UI; vitamina K3, 5mg; vitamina B12, 25mg; tiamina (vitamina B1), 2mg; riboflavina (vitamina B2), 8mg; piridoxina (vitamina B6), 2mg; biotina, $100 \mathrm{mg}$; ácido fólico, $0,5 \mathrm{mg}$; ácido pantotênico, $15 \mathrm{mg}$; niacina, 40mg e colina 350mg; ferro, 40mg; cobre, $8 \mathrm{mg}$; manganês, $70 \mathrm{mg}$; cobalto, 0,5mg; iodo, $2 \mathrm{mg}$; selênio, $0,2 \mathrm{mg}$ e zinco, $50 \mathrm{mg}$.

foram: temperatura da água - termômetro comum de coluna de mercúrio (registrada duas vezes ao dia, pela manhã -às $8 \mathrm{~h}$, e à tarde-às $17 \mathrm{~h} ; \mathrm{pH}$ potenciômetro digital (Corning PS-30); alcalinidade e oxigênio dissolvido - método colorimétrico (BOYD \& TUCKER, 1992); condutividade elétrica - condutivímetro digital (Corning PS-70). O arraçoamento foi realizado quatro vezes ao dia (8, 13,18 e $23 \mathrm{~h}$ ), à vontade. As caixas eram sifonadas diariamente para a retirada do excesso de alimento.

\section{RESULTADOS E DISCUSSÃO}

A temperatura da água dos aquários experimentais oscilou, em média de 27,5 a $30,5^{\circ} \mathrm{C}$, entre os dados obtidos pela manhã e a tarde. $\mathrm{O}$ pH da água apresentou-se alcalino, variando entre 7,6 a 8,3. As concentrações de oxigênio dissolvido da água dos tanques variaram de 4,7 a 6,06ppm. MOURA \& SENHORINE (1996) recomendam, para larvas de Brycon cephalus, ração de tamanho entre 0,30-0,35mm para larvas de 9,8 a 15,9mm, correspondendo à primeira semana de vida. No presente ensaio, utilizamos peneiras de malha 0,25mm para a mesma fase, mostrando que para a espécie utilizada, é necessário grânulos menores para a ingestão do alimento.

PELLI et al. (1997) verificaram o início de ingestão de ração para larvas de curimbatá (Prochilodus scrofa), em tanques de piscicultura sob sistema semi-intensivo de cultivo. Os autores verificaram que o início da ingestão se dá no $8^{\circ}$ dia após a eclosão. Neste experimento, foi observado que as 
larvas de curimbatá apresentaram uma boa aceitação com relação à alimentação artificial, que foi oferecida a partir do $9^{\circ}$ dia de vida.

HAYASHI et al. (1998) avaliaram o efeito da utilização de plâncton e dieta artificial (24 e 30\% de proteína bruta) na alimentação do curimbatá (Prochilodus lineatus) na fase inicial, durante um período de 30 dias e concluíram que, nas condições do trabalho, a dieta contendo $24 \%$ de proteína bruta, associada ao plâncton, mostrou-se mais adequada para o curimbatá na fase inicial $(100,95 \mathrm{~g}$ de ganho de peso e $95 \%$ de sobrevivência). Neste experimento, verificou-se que o maior nível protéico (40\%) proporcionou os melhores ganhos de peso.

CANZI et al. (1992) observaram baixas taxas de sobrevivência em larvas de pacu (Piaractus mesopotamicus), durante o período larval, quando a taxa de mortalidade das larvas arraçoadas com dieta artificial foi de $100 \%$, 95\% para as larvas alimentadas com ovo seco desidratado e $70 \%$ para as que receberam alimento natural. PORTELLA et al. (1998) observaram taxas de sobrevivências para larvas de curimbatá (Prochilodus scrofa) alimentadas com dietas vivas e artificiais enriquecidas com várias fontes de ácidos graxos, de $52,62 \%$ e $63,12 \%$ respectivamente. Através da tabela 2, pode-se verificar que, após 45 dias de experimentação, os dados de sobrevivência das larvas não mostraram diferenças estatisticamente significativas com relação aos efeitos dos teores de proteína bruta $(92,4 \pm 6,09$ e $89,43 \pm 6,09$ para os níveis protéicos de 35 e $40 \%$ de proteína bruta) e as diferentes densidades de estocagem utilizadas $(95,56$ $\pm 9,13 ; 90,55 \pm 9,13$ e $86,65 \pm 9,13$ para as densidades de estocagem de 0,$5 ; 0,75$ e 1,0 larva/litro). BASILE-MARTINS et al. (1990) cultivaram larvas de curimbatá (Prochilodus scrofa) com três dias de vida, na densidade de 40 larvas/litro e submetidas a quatro tratamentos com rotífero e plâncton selvagem em diferentes proporções. Após 20 dias, a taxa de sobrevivência média foi de 84,4 ; 92,1 e $95 \%$ para as larvas alimentadas com 300, 450 e 600 rotíferos/larva/dia e 39,2\% para as larvas alimentadas com 300 itens/larva/dia de plâncton selvagem.

Estudando a interação dos dois efeitos principais dos tratamentos sobre os dados de ganho de peso das larvas (Tabela 3), durante o período de 30 dias, observou-se que o teor de proteína bruta na dieta só tem efeito estatisticamente significativo $(\mathrm{P}<0,05)$ na densidade de estocagem de 0,5 larva/litro e que a maior média foi proporcionada pela ração com teor protéico de $40 \%$ de $\mathrm{PB}(1,66 \mathrm{~g})$.

Considerando os resultados observados em um período experimental maior (68 dias), as análises de variância revelaram diferenças significativas, a 5\% de probabilidade, somente para os efeitos do teor protéico da dieta sobre os dados de peso, ou das densidades de estocagem sobre a sobrevivência das larvas. Ainda assim, o teste de Tukey para comparação de médias $(\mathrm{P}<0,05)$ revelou que o melhor valor para o peso foi proporcionado

Tabela 3 - Valores médios do peso final das larvas (g) na interação entre densidades de estocagem e teores protéicos na dieta.

\begin{tabular}{lcccc}
\hline \multirow{2}{*}{ Níveis de PB na } & \multicolumn{3}{c}{ Densidades (larvas/litro) } & (DMS) \\
\cline { 2 - 4 } Dieta (\%) & 0,5 & 0,75 & 1,00 & \\
\hline 35 & $1,0967^{\mathrm{bA}}$ & $1,0267^{\mathrm{aA}}$ & $0,8833^{\mathrm{aA}}$ & $(0,2615)$ \\
40 & $1,6600^{\mathrm{aA}}$ & $1,2067^{\mathrm{aB}}$ & $0,7900^{\mathrm{aC}}$ & $(0,2615)$ \\
$(\mathrm{DMS})$ & $(0,2137)$ & $(0,2137)$ & $(0,2137)$ & \\
\hline
\end{tabular}

Médias seguidas de mesma letra não diferem, significativamente entre si, pelo teste de Tukey $(\mathrm{P}<0,05)$. Letras minúsculas comparam médias em cada coluna, e letras maiúsculas comparam médias em cada linha. 
pela dieta de maior conteúdo protéico $(2,05 \mathrm{~g} \pm 0,41)$ e as melhores taxas de sobrevivência foram obtidas na densidade de estocagem de 0,5 larvas/litro $(94,45 \pm 19,33)$. FONTES \& SENHORINI (1992) avaliaram o efeito de três densidades de estocagem no desenvolvimento de larvas de pacu (Piaractus mesopotamicus). Após 30 dias de criação, os resultados para peso e sobrevivência média foram $1,55 \mathrm{~g}$ e $44,0 \%, 0,70 \mathrm{~g}$ e $23,0 \%$ e $0,40 \mathrm{~g}$ e $23,0 \%$ para as densidades de estocagem de 40 , 80 e 160 larvas $/ \mathrm{m}^{3}$, respectivamente.

Estudando os resultados de peso das larvas através do teste de Tukey, ao nível de 5\% de probabilidade, durante os primeiros 45 dias de experimentação, observou-se, no desdobramento apresentado na tabela 3 , que o maior teor protéico utilizado nas dietas $(40 \% \mathrm{~PB})$ só tem efeito $(\mathrm{P}<0,05)$ sobre as médias, quando utilizada a densidade mais baixa de larvas. $\mathrm{Na}$ verdade, só quando recebiam a dieta contendo $40 \%$ PB é que as larvas manifestaram os efeitos da elevação da densidade de estocagem sobre as médias de peso que diminuíram progressivamente.

DIAS (1989) relata que as proteínas são continuamente utilizadas para a construção de tecidos e as exigências de proteína bruta pelos peixes variam muito em função do tamanho dos peixes, disponibilidade de alimento natural, quantidade e qualidade do alimento fornecido e teor protéico da dieta. Portanto, a melhor média para o peso das larvas foi proporcionada, nesta fase, pelo tratamento correspondente ao uso de $40 \%$ de proteína bruta na dieta, com a densidade de 0,5 larva/litro (Figuras 1 e 2).

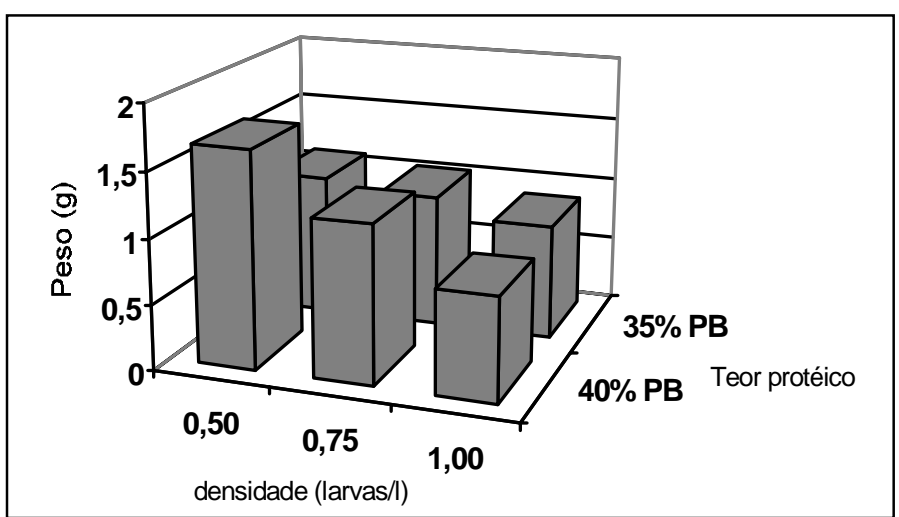

Figura 1 - Peso médio (g) das larvas de curimbatá (Prochilodus scrofa) aos 68 dias de experimento.

\section{CONCLUSÕES}

Os dados obtidos permitem, nas condições experimentais, as seguintes conclusões: 1) a alimentação artificial pode ser administrada, exclusivamente, às larvas de curimbatá a partir do $9^{0}$ dia de vida; 2) a melhor média para os pesos das larvas foi proporcionada, nos primeiros 45 dias experimentais, pelo tratamento correspondente ao uso de $40 \%$ de PB na dieta, com a densidade de 0,5 larva/litro; 3 ) em um período experimental maior (68 dias), há diferença significativa $(5 \%$ de probabilidade) somente para os efeitos do teor protéico da dieta sobre os dados de peso, ou das densidades de estocagem das larvas. $\mathrm{O}$ melhor valor para o peso é proporcionado pela dieta de maior conteúdo protéico.

\section{REFERÊNCIAS BIBLIOGRÁFICAS}

BASILE-MARTINS, M.A. Criação de organismos para alimentação de larvas de peixes. In : SIMPOSIO BRASILEIRO DE AQÜICULTURA, 3. São CarlosSP. Anais... São Carlos : USFCar e CESP. 1984. 705p. p.97-100.

BASILE-MARTINS, M.A., PORTELLA, M.C., CESTAROLLI, M.A., et al. Larvicultura do curimbatá Prochilodus scrofa STEINDACHNER, 1882. In: SIMPÓSIO BRASILEIRO DE AQÜICULTURA, 6, Natal - RN, Anais..., 1990, p.33, 107p.

BOYD, C.E., TUCKER, C.S. Water quality and pond soil analyses for aquaculture. Auburn: Auburn University, 1992. 187p.

CANZI, C., BORGUETTI, J.R., FERNANDEZ, D.R. The effects of different treatments on the survival and development of pacu larvae (Piaractus mesopotamicus). Arq Biol Tecnol, v.35, n.1, p.117$127,1992$.

Ciência Rural, v. 31, n. 1, 2001. 
CAStagnolli, N. Piscicultura de água doce. Jaboticabal SP : FUNEP, 1992. 189p.

DIAS, T.C.R. Desenvolvimento de larvas de pacu (Piaractus mesopotamicus, HOLMBERG, 1887) com dietas naturais e artificiais. Jaboticabal, 1989. 53p. Dissertação (Mestrado em Zootecnia) - Faculdade de Ciências Agrárias e Veterinárias/Jaboticabal, Universidade Estadual Paulista. 1989.

FONTES, N.A., SENHORINI, J.A. Larvicultura do pacu (Piaractus mesopotamicus, HOLMBERG, 1887) (Pisces Characidae) em diferentes densidades de estocagem. In: SIMPÓSIO BRASILEIRO DE AQÜICULTURA, 7 e ENCONTRO NACIONAL DE PATOLOGIA DE ORGANISMOS AQUÁtICOS, 2. Peruíbe-SP. Anais..., ACIESP, 1992. 260p. p.29.

HAYASHI,C., FURUYA, V.R.B., SOARES, C.M., et al. Plâncton e dieta artificial na alimentação do "curimbatá" (Prochilodus lineatus), na fase inicial. In: AQUICULTURA BRASIL'98. Recife, PE. Anais... Recife : Persona, 1998. p.28. 253p.
MOURA, M.M. de, SENHORINE, J.A. Determinação do tamanho da dieta alimentar para larvas de matrinxã, Brycon cephalus.. In: SIMPÓSIO BRASILEIRO DE AQÜICUlTURA, 9, Sete lagoas, MG. Anais... Sete Lagoas: Real Impressos, 1996. 180p. p.76.

PELli, A., DUMONT NETO, R., SILVA, J.D. DA $\boldsymbol{e}$ t al. Ingestão de ração por pacu (Piaractus mesopotamicus Holmberg, 1887), curimba (Prochilodus scrofa Steindachner, 1881) e piau (Leporinus friderici Bloch, 1794) em condições semi-intensivas. B Inst Pesca, São Paulo, v.24, n. especial, p.119-123. 1997.

PORTELlA, M.C., VERANI, J.R., FERREIRA, J.T.B., et al. Desempenho de crescimento e composição corporal de larvas e alevinos de Prochilodus scrofa alimentados com dietas vivas e artificiais, enriquecidas com várias fontes de ácidos graxos. In: AQUICULTURA BRASIL'98, 1998, Recife, PE. Anais... Recife : Persona, 1998. 253p. p.12.

TACON, A.G.J. Nutrição e alimentação em Aqüicultura: Um acesso prático à pesquisa e desenvolvimento. In: SIMPÓSIO LATINOAMERICANO DE AQÜICULTURA, 6 e SIMPÓSIO BRASILEIRO DE AQÜICULTURA, 5., 1988, Florianópolis, SC. Anais... Aciesp, 1988. 807p. p.74-997p.

Ciência Rural, v. 31, n. 1, 2001. 